\title{
For the Best Customer Data, Look Beyond the Market
}

\author{
Jon Eckhardt (University of Wisconsin-Madison)
}

KEYWORDS: Entrepreneurship, Innovation, Product Development, Strategy, Technology Commercialization.

Seed stage entrepreneurs must grapple with how they will scale their businesses. While this process includes many steps, discovering the proper product/market fit for the business is critical early on. A fledgling business will ultimately fail if it never finds a pool of target customers whose needs have not yet been sufficiently met.

To figure this out, many entrepreneurs look at what competitors have been doing, or they ask potential customers what they want. But our research has shown that more freely available, reliable data can be found in an unexpected place: people who are using early versions of a product, service or technology that has not yet been commercialized. By studying these passionate "early adopters," entrepreneurs can glean information that can be used to identify the potential market acceptance of a more complete version of the product.

\section{Customer-Centric Market Discovery}

Customer-centric approaches towards finding product/market fit - such as the Lean Startup - say entrepreneurs should find out what customers want by working closely with them while developing the product, instead of building the product and then seeing whether the team can find a market for it. Within this framework, a potential product feature is treated as a product hypothesis. Each hypothesis is tested by building the feature and testing market receptiveness with a group of beta customers. Product/market fit is discovered when the iterative process produces a product with features that an identifiable group of customers are willing to buy.

Within this framework one might ask: where do product hypotheses come from? Proponents of the lean startup approach recommend that entrepreneurs interview customers to identify product hypotheses to build and test. Customer interviews can be valuable because they can keep entrepreneurs focused on the task of serving the needs of actual people. But they have drawbacks. Researchers and entrepreneurs know that hypotheses developed from customer interviews can be misleading

in ways that are difficult to detect. This is especially true if the questions are poorly formulated. Questions such as: "Would you use this product?" or "What would you pay for a product like this?" tend to attempt to validate one's own product rather than the actual problem the product is intended to service.

\section{Using Data for Hypothesis Generation}

Existing data, especially when combined with interview data, can be a powerful source of information that can be used to generate product hypotheses.

In my experience, market-focused entrepreneurs often overlook the full range of existing data available on user experiences when searching for product/market fit. As indicated by the table below, technologies and products that generate user data can be thought of as being made available under four different economic logics.

Commercial logics. Economic logics \#1 and \#3 are well known to most entrepreneurs as they represent technologies that are made available to users by commercial providers. Logic \#1 refers to products and services that are made available for free as part of a forprofit business model, such as advertising-based businesses or try-before-you-buy pricing models. Logic \#3 refers to for-profit business models where customers must pay to use a product or service.

Non-Commercial logics. Many entrepreneurs overlook the information on user preferences that noncommercial actors generate. These actors, such as individual hobbyists, nonprofits and associations, often produce technologies that provide data about the existence of potential products. For example, the founders of Apple-Steve Jobs and Steve Wozniak-were members of the Homebrew Computer Club. Members of the Club produced and used early computer technologies. Their activity generated data about potential features that became embodied in early

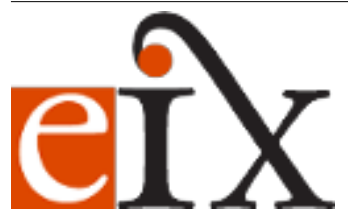

Copyright ( $) 2017$ The Authors. Entrepreneur \& Innovation Exchange is published at EIX.org. This is an open access article under the terms of the Creative Commons Attribution-NoDerivs License, which permits use and distribution in any medium, provided the original work is properly cited and no modifications or adaptations are made. View EIX.org Authorship Terms at https://eix.org/terms 
commercial computers. Non-commercial producers also make available a wide range of artifacts such as sporting equipment, food and software.

Non-commercial actors produce artifacts for free (economic logic \#2) and also for a fee (economic logic \#4). While most readers are aware that programmers often give away software for free, actors make available a wide range of artifacts under economic logic \#2, ranging from food (such as pies distributed for free at potlucks) to services. For example, individuals who attend a potluck may notice that a particular dish, such as a pie, is popular and hence discover a recipe for a product that might be viable as a commercial product. Non-commercial actors also produce artifacts for a fee (economic logic \#4). For example, academic research labs often sell biological materials to others at a cost to fund their continued research. These operations are often small and focused on cost recovery instead of a becoming a business.

Figure 1

\begin{tabular}{|c|c|c|}
\hline & $\begin{array}{c}\text { Distributed for } \\
\text { free (Price=0) }\end{array}$ & $\begin{array}{c}\text { Distributed for } \\
\text { a price (Price }> \\
\text { 0) }\end{array}$ \\
\hline Commercial & $\begin{array}{c}\mathbf{1} \\
\text { Indirect Profit } \\
\text { Model }\end{array}$ & $\begin{array}{c}\mathbf{3} \\
\text { Direct Profit } \\
\text { Model }\end{array}$ \\
\hline $\begin{array}{c}\text { Non- } \\
\text { commercial }\end{array}$ & $\begin{array}{c}\text { No Revenue } \\
\text { Model }\end{array}$ & Revenue Model \\
\hline
\end{tabular}

Source: Figure reproduced from Welcome Contributor or No Price Competitor? The Competitive Interaction of Free and Priced Technologies.

Economic logics \#1 and \#3 certainly generate useful public information about user preferences. However, it creates a fundamental problem for startup entrepreneurs using this information for hypothesis generation: the data shows a competitor has already discovered the market. This means that the entrepreneur is likely to be forced into trying to catch a market leader instead of starting as a market pioneer.

However, artifacts that are distributed under noncommercial logics are often non-competitive and hence are likely to produce more valuable insights to shape the customer hypothesis. People operating under these logics are often sharing the artifact because they are primarily interested in the technology itself or in finding solutions to their own individual needs, instead of meeting the needs of consumers. This means that noncommercial actors are unlikely to actively work to build features to meet specific groups of paying customers, and they are unlikely to invest in supporting structures - such as customer service - that are required to meet the needs of paying customers. This creates opportunities for the entrepreneur to take the product to that next level.

\section{Harnessing Product Information from Non-Commercial Actors}

Non-commercial actors also provide low-cost information to seed-stage entrepreneurs. In many cases, these actors work out of passion towards a specific industry. And in many cases, they actively avoid involving themselves in any form of business because they view it as detracting from their passion. This provides opportunities for those who wish to operate under the commercial logic. Non-commercial actors may be willing to sell their technologies or even partner with others if they are assured it won't inhibit their ability to continue working on their passions. This was the case for Wozniak, whose partnership with Steve Jobs was conditional on the fact that Jobs would handle the commercial operations of the business.

\section{What the Research Showed}

In a study of over 16,000 mobile apps over 36 months (February 1, 2004- February 28, 2007), our research showed that the presence of free mobile apps within a specific market category likely spurred sales among priced mobile apps introduced within the same category. This goes against the conventional assumption that free mobile apps would act as substitutes for its priced equivalents, thus reducing sales.

\section{Applying the Research}

Our findings showed that entrepreneurs forming businesses in new markets may benefit from explicitly seeking out information produced by non-commercial actors to help determine product/market fit. In the case of mobile apps, the research suggests that commercial producers could learn more rapidly about customer needs by closely monitoring the success of free noncommercial apps. This finding is likely to hold true for non-commercial software available in general. However this work is likely to apply to markets far beyond software. For example, an alert entrepreneur may discover a new food product at a summer potluck. A list of potential sources of non-commercial information include: 
1.

Academic journal articles, academic conferences, and university research labs. Academic journals can at times describe technologies, procedures and processes that are not yet turned into products

2.

Public blogs and exchange events (such as the HHS IDEA Lab, Pinterest, or Reddit). Public blogs can feature individuals describing problems they are trying to solve or even early solutions they have created to a problem they have.

3.

Clubs and hobbyist groups. The Apple cofounders met at the Homebrew Computer Club in Silicon Valley, where both were members. At the time Steve Wozniak was experimenting with computers for his own use.

4.

User reviews and comments. User reviews and comments can provide insight into problems that potential customers might have as well as solutions they have have come up with on their own.

\section{Summary}

This research assessed the relationship between freely released technologies and priced technologies within a similar category. The findings and postulates derived were based off a study of the mobile app market for the Palm computing platform; however they can be easily applied to markets outside of software. Results of the research found that mobile app categories with a growing number of freely released mobile apps provided for increased sales among priced mobile apps released within the same category. It is reasonable to infer from the study that the information generated from both commercial and non-commercial actors can be utilized by seed stage entrepreneurs in finding a proper product/market fit. The data collected from these actors can be effectively used to create customer and product feature profiles and make it more surefooted and less costly to develop the product. As many seed stage entrepreneurs are often cash-strapped, the low-cost information helps entrepreneurs to pose practical questions, identify important issues and gauge solutions regarding their own product prior to release.

\section{References}

1. Eckhardt JT. Welcome contributor or no price competitor? The competitive interaction of free and priced technologies. Strategic Management Journal. 2015; 